\title{
Quality by Design (QbD) Assisted Fabrication of Fast Dissolving Buccal Film for Clonidine Hydrochloride: Exploring the Quality Attributes
}

\author{
Pankaj V. Dangre $(\mathbb{D}$, Ram D. Phad $(\mathbb{D}$, Sanjay J. Surana $(\mathbb{D}$, and Shailesh S. Chalikwar $(\mathbb{D}$ \\ Department of Pharmaceutics and Quality Assurance, R. C. Patel Institute of Pharmaceutical Education and Research, \\ Shirpur 425405, Maharashtra, India \\ Correspondence should be addressed to Shailesh S. Chalikwar; pharmashailesh@rediffmail.com
}

Received 11 June 2018; Revised 17 March 2019; Accepted 14 April 2019; Published 5 May 2019

Academic Editor: Katja Loos

Copyright (c) 2019 Pankaj V. Dangre et al. This is an open access article distributed under the Creative Commons Attribution License, which permits unrestricted use, distribution, and reproduction in any medium, provided the original work is properly cited.

\begin{abstract}
The present work endeavors fabrication of fast dissolving buccal film of clonidine hydrochloride by employing quality by design (QbD) based approach. The total nine formulations were prepared according to formulation by design helped by JMP software 13.2.1. The patient oriented quality target product profiles were earmarked and on that basis critical quality attributes were identified. Preliminary screening studies along with initial risk assessment eased the selection of film-forming polymer (HPMC E 15) and plasticizer (PEG 400) as CMAs for formulation of films. A $3^{2}$ full factorial plan was utilized for assurance of impact, i.e., HPMC E15 $\left(\mathrm{X}_{1}\right)$ and PEG $400\left(\mathrm{X}_{2}\right)$, as independent variables (factors) on thickness $(\mathrm{mm})\left(\mathrm{Y}_{1}\right)$, disintegration time (s) $\left(\mathrm{Y}_{2}\right)$, folding endurance $\left(\mathrm{Y}_{3}\right)$, and tensile strength $(\mathrm{kg})\left(\mathrm{Y}_{4}\right)$. Furthermore, prediction profiler assists in predicting composition of best formulation encompassing desired targeted response. The optimized formulation (F6) showed fast drug dissolution (>90\%) within $8 \mathrm{~min}$, and solid state characterization by DSC, XRD revealed excellent film characteristics. In a nutshell, the fast dissolving buccal film for clonidine hydrochloride was successfully developed assisted by QbD approach with markedly improved biopharmaceutical performance as well as patient compliance.
\end{abstract}

\section{Introduction}

Clonidine Hydrochloride (CLH) is an antihypertensive drug that has a well-established safety profile in the treatment of hypertension. It prevents a problem of high blood pressure such as myocardial infarction and stroke. Further, it also used to prevent menopausal symptoms and symptoms of opioid withdrawal [1]. CLH is an $\alpha 2$-adrenoceptor agonist, which has both peripheral and central effects [2]. CLH is freely soluble in water, ethanol, and slightly soluble in chloroform. It is in white crystalline powder form, stable in light, air, and room temperature [3]. It has molecular weight of 266.6 [4]. CLH is well absorbed from the gastrointestinal tract; however, its oral bioavailability in humans is poor which suggests extensive first pass metabolism of the drug. It has a half-life of 12-16 h [3]. The daily effective dose of CLH is in the range of $0.1-0.2 \mathrm{mg}$, and nearly $65 \%$ of which is eliminated through kidney and 20\% through faces [5]. Taking the above ideal properties of CLH into the consideration, to best of our knowledge, we have planned to prepare fast dissolving buccal film (FDBF) of CLH as no attempt has been reported in the literature.

Hypertension is defined as the systolic blood pressure $\geq 140 \mathrm{mmHg}$ and diastolic blood pressure $\geq 90 \mathrm{mmHg}$ [6]. The aim of preparation of FDBF is to reduce the dissolution time which gives quick onset of action and also avoid the first pass metabolism of model drug. The several studies reported the benefits of giving CLH by sublingual route over oral administration as later route associated with dry mouth, fatigue, hypotensive effect [5], and swallowing difficulty [7, 8]. Further, sublingual administration of CLH was reported to be effective, simple, and safe [9].

In spite of astounding development in drug delivery system, the oral route of drug administration is still considered as a most preferred route of administration for systemic effect because of self-medication, ease of administration, and 
avoidance of pain compared to a parenteral route [10]. Typically geriatric, pediatric, and bedridden patient pose difficulties in swallowing the conventional oral dosage forms such as tablets and capsules to overcome this problem [11]. A novel formulation was developed in late 1970s, i.e., FDBF as an alternative to tablets, capsules, syrups, and other formulations [12], with several inherent advantages over traditional tablet and liquid formulations [10]. The only commercially available oral formulation of CLH is a tablet. FDBFs are advanced, versatile oral solid dosage form due to its more flexibility and comfort. The advantage of these films over oral rapid dissolving tablets is that the films do not deliver a feeling of foreign body to patients, thus avoiding the spit-out of dosage form [13]. Kinds of literature reveal that developed liquid formulation, containing CLH [1], has its own limitations. Thus FDBF is very thin strip and gives better efficacy by dissolving drug within a second (s) in the oral cavity after the contact with saliva without chewing and it also avoids the use of water for its administration. It gives fast absorption which in turn leads to higher bioavailability of the model drug because of high regional blood flow along with the higher permeability (4-1000 times greater than that of skin) of oral mucosa $[9,10]$. Furthermore, FDBF prevents first pass metabolism which leads to more availability of drug in blood [14].

In recent years, the development process of pharmaceutical preparation has changed. Quality by design $(\mathrm{QbD})$ is a methodology used to build quality into products, by design [15]. The QbD approach is used to ensure the pharmaceutical development is conducted in arrange to have in the end a systematic understanding of how process parameters affect a product [16]. According to ICH (International Conference Harmonization) Q8, QbD can be defined as "a systematic approach towards development that begins with predefined objectives and emphasizes product and process understanding and process control, based on sound science and quality risk management" [17]. A very common tool or element used in the $\mathrm{QbD}$ is the quality target product profile (QTPP), which can be defined as "a dynamic product description that summarizes the quality characteristics expected to guarantee the product performance, stability, safety, and efficiency". Mainly, QTPP includes the critical quality attributes (CQAs) and critical process parameters (CPPs). CQAs might be continued as attributes that characteristic of product quality and CPPs refers to critical process parameters or variables that can impact these characteristics. Therefore, the mix of the CQAs and CPPs allows the explanation of design space. The preparation of FDBF and QTPP may be organized based on earlier reported studies considering the essential requirements for manufacturing as well as techniques available for its characterization to get the desired film properties. A prepared FDBF should be handled without being harmed, ought to be physically stable and give a simple and pleasant administration. These properties may be translated into product quality attributes, such as appropriate organoleptic and mechanical properties [15].

FDBFs of CLH can be visualized as a thin elegant, unobstructive, mucoadhesive film coupled with performance features of fast dissolution and rapid release that does not require special packaging. It can be carried in a patient's pocket, wallet, or pocket book. Therefore, objective of present work is to develop and evaluate FDBF of CLH based on QbD approach that can be considered as superior alternative to a marketed formulation in terms of its performance and patient acceptability. Moreover, these FDBFs are gaining interest nowadays due to their ability to achieve rapid drug onset through sublingual and buccal route. The formulated films were evaluated of physicochemical properties by using $\mathrm{X}$ ray diffraction (XRD) and differential scanning calorimetry (DSC). These films were also evaluated for drug dissolution study, in vitro disintegration time, surface $\mathrm{pH}$, folding endurance, tensile strength, etc.

\section{Materials and Methods}

2.1. Materials. Clonidine hydrochloride was a generous gift of Unichem Laboratories Ltd. Goa, India. HPMC E -15 (Hydroxy propyl methyl cellulose) was procured from SigmaAldrich Chemicals Pvt. Ltd., Mumbai, India. Xylitol was gifted by Cipla Ltd. Mumbai, India. All other chemicals and reagents utilized were analytical grades.

\subsection{Methods}

2.2.1. Assigning of $\mathrm{QTPP}$ and $C Q A$. The $\mathrm{QbD}$ approach was initiated with proper selection and assignment of QTPP encompassing the proactive summary for utilizing the maximum benefits of developed formulation. Pharmaceutical development of FDBF containing CLH begins with the assignment of critical process and formulation attributes through the QTPP. Patient-centric approach mainly focuses on a safe efficacious use of FDBF that will facilitate patient compliance with rapid onset of drug action. The CPP for FDBF should be robust, reproducible, and should result in a product that meets the appropriate specification. Each CPP was subjectively positioned as high-, medium-, or low-risk(s) level thinking about the likelihood of risk and severity of associated impact on the CQAs.

2.2.2. Risk Assessment. Risk assessment studies were executed to identify the critical material attributes (CMA) or CPPs having significant influence on CQAs of FDBF. An Ishikawa fish-bone diagram (Figure 1) was portrayed to enlist the potential high-risk factors that affect quality of final formulation. The list encompasses nuance of key material attributes and/or process variables for development of FDBF containing CLH.

2.2.3. Design of Experiment (DoE). Design of experimentation (DoE) is a systematic study to determine the interaction between material and/or process parameters on the performance of final formulation. In the present study, a $3^{2}$ full factorial design approach was utilized to investigate the influence of various independent variables on dependent variables. Statistical software JMP ${ }^{\circledR 13.2 .1 ~(S t a t i s t i c a l ~ A n a l y s i s ~ S o f t-~}$ ware; SAS Institute Inc., North Carolina, US) was employed to perform design of experiments. Independent variables 


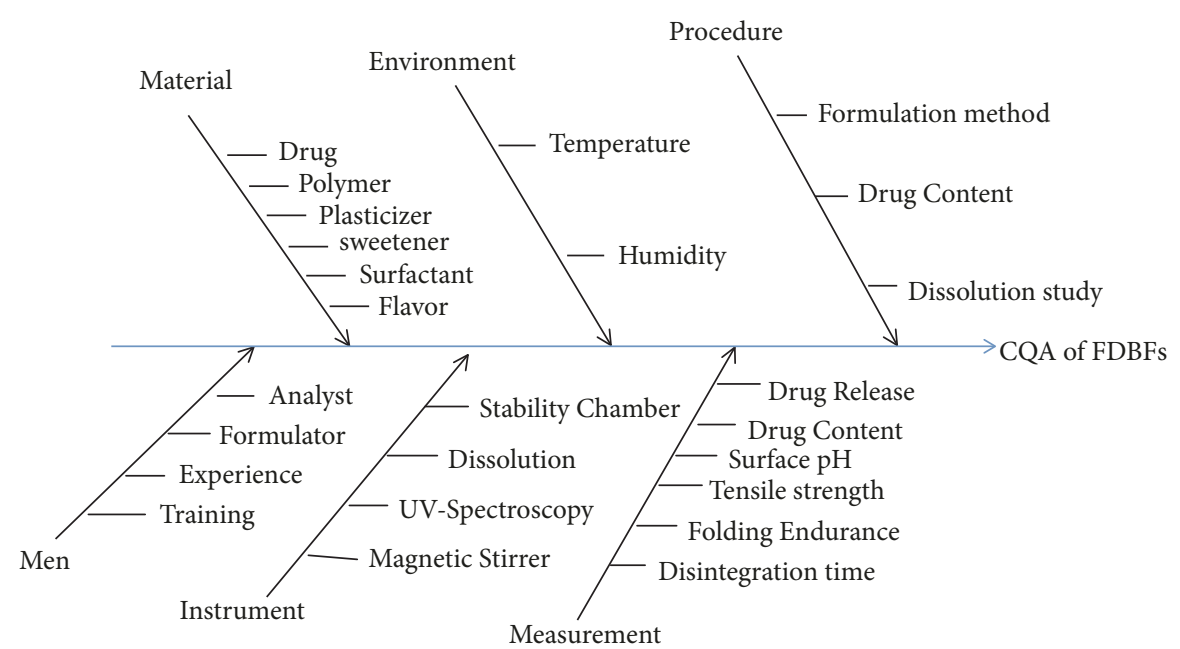

FIGURE 1: Ishikawa fish-bone diagram depicting the cause and effect relationship among the formulation and process variables.

(factors), e.g., HPMC (Hydroxy propyl methyl cellulose) E15 (\%) $\left(\mathrm{X}_{1}\right)$ and PEG (Polyethylene glycol) $400(\%)\left(\mathrm{X}_{2}\right)$ and the dependent variables (response), e.g., thickness $(\mathrm{mm})\left(\mathrm{Y}_{1}\right)$, disintegration time $(\mathrm{s})\left(\mathrm{Y}_{2}\right)$, folding endurance $\left(\mathrm{Y}_{3}\right)$, and tensile strength $(\mathrm{kg})\left(\mathrm{Y}_{4}\right)$ were studied and analysis of variance (ANOVA) was performed. The selections of factors $\left(\mathrm{X}_{1} \& \mathrm{X}_{2}\right)$, as well as their levels, were completely based on preliminary trials conducted to ensure formation of FDBF. Table 1 depicts the DoE runs with defined dependent variables along with other ingredients for the formulation of FDBF. All experimentations were runs in a random fashion with each formulation batch. Total of 9 experimentation runs were allotted and accordingly each formulation was developed.

\subsubsection{Fabrication of Fast Dissolving Buccal Film (FDBF).} FDBF of CLH was fabricated by a solvent-casting technique employing hydroxyl propyl HPMC- E15, PEG-400, and other suitable ingredients (Table 1). HPMC E-15 in different proportions, i.e., $2,2.5$, and $3 \% \mathrm{w} / \mathrm{w}$, and PEG- $400(2,4$, and $6 \% \mathrm{w} / \mathrm{w}$ ) were mixed with $10 \mathrm{~mL}$ of distilled water followed by continuous stirring for $30 \mathrm{~min}$. The solution was then kept aside for $1 \mathrm{~h}$ to escape the entrapped air bubbles in a mixture. In another baker; CLH, citric acid, sodium lauryl sulphate (SLS), xylitol, and lemon flavor were dissolved in sufficient amount of water and mixed with first polymeric solution in a drop-wise manner with continuous stirring. The solution was left for $30 \mathrm{~min}$ for removal of entrapped air bubbles. The solution was poured on a Petri-plate (diameter $9 \mathrm{~cm}$ ) and dried at ambient room temperature for $24 \mathrm{~h}$. A dried film was carefully scratched from Petri-plate and inspected for appearance and integrity. Finally, suitable films were cuts into a required size $(2 \times 2 \mathrm{~cm})$ containing a therapeutic dose of CLH $(0.2 \mathrm{mg})$. The films were packed in polyethylene strip and stored at normal room temperature until further evaluation.

\subsection{Characterizations of FDBF}

2.3.1. Measurement of Thickness. The thickness of prepared FDBF films was measured by using digital vernier caliper
(Mitutoyo, Japan). Measurements at four different corners of films were taken and their mean average was calculated [18].

2.3.2. Estimation of Drug Content. Estimation of drug content was made to ensure a uniform dispersion of drug throughout the films. Each film was dissolved in $10 \mathrm{~mL}$ phosphate buffer $(\mathrm{pH}$ 6.8) placed in volumetric flask and then stirred until complete dissolution of film. The solution was filtered and drug was estimated spectrophotometrically (UV-Spectrophotometer, Shimadzu 1700) by measuring absorbance at $271 \mathrm{~nm}$ [19].

2.3.3. Estimation of Disintegration Time. It is a time after which film collapse when brought into contact with water. It is estimated by placing the desired film in Petri-plate containing $25 \mathrm{~mL}$ of water and time was noted after complete disintegration or collapsing of film. The disintegration time limits, i.e., 30 s or less, is considered optimum $[8,20]$.

2.3.4. Estimation of Folding Endurance. Folding endurance is a key parameter which reveals a mechanical characteristic of film. A good film should be able to withstand minimum tear and wear as well as maintain its integrity during administration. It is estimated by repeatedly folding the film at a particular point for more than 200 times. A high number of folding endurances indicate good mechanical strength of a film [21].

2.3.5. Estimation of Moisture Absorption (\%). Estimation of moisture absorption by film was carried out in a desiccator saturated with salt solution, i.e., $\mathrm{KCl}$, to maintain a relative humidity (84\%). Preweighted films were kept in desiccator at room temperature for $24 \mathrm{~h}$. Thereafter, each film was 


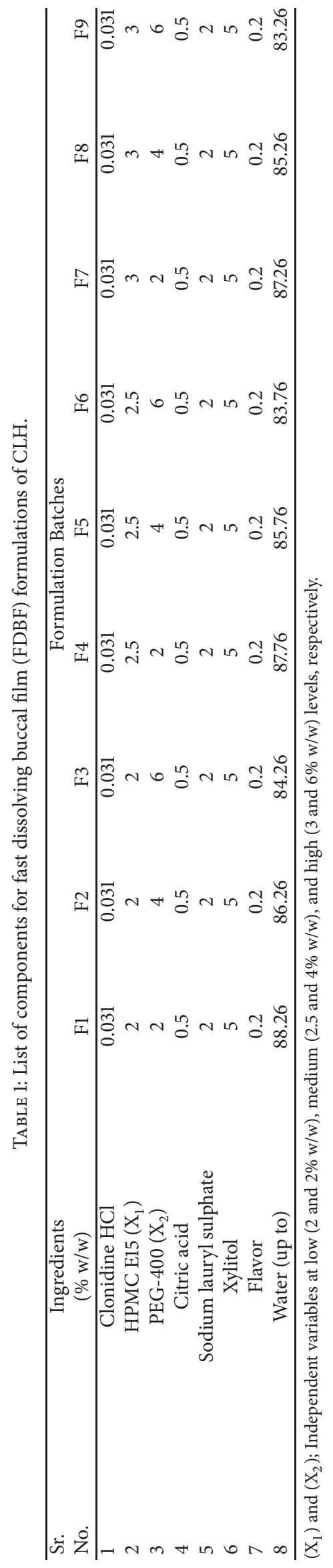


reweighed and moisture uptake by a film was calculated from the following equation [22].

Percentage moisture uptake

$$
=\left(\frac{(\text { Final Wt. }- \text { Initial Wt. })}{(\text { Final Wt. })} \times 100\right)
$$

2.3.6. Estimation of Tensile Strength. Tensile strength of the films was determined by Texture analyzer testing machine (Texture Pro CT V1.3 Build 15, Brookfield). It comprises two load cell grasps, bringing down one which is settled and the upper one is movable. Each film was settled between these cell holds and power was progressively applied till the film breaks. The tension $(\mathrm{kg})$ required to break the films was indicated by the dial reading. All measurement was performed in triplicate [23].

2.3.7. Estimation of $\mathrm{pH}$ (Film Surface). The $\mathrm{pH}$ of film surface was estimated by little modification with a previously reported method. Each film was wetted with sufficient amount of double distilled water and then allowed to equilibrate for $30 \mathrm{~min}$ in Petri-plate. The $\mathrm{pH}$ electrode was brought into contact with the surface of wet film and $\mathrm{pH}$ was digitally displayed by $\mathrm{pH}$ meter (pH system 362, Systronics) [24].

2.3.8. In Vitro Drug Dissolution Study. The in vitro dissolution study of FDBF's was performed by using USP-XXVI dissolution apparatus type-I (basket type). The dissolution medium consists of $300 \mathrm{~mL}$ of phosphate buffer $(\mathrm{pH}$ 6.8) maintained at $37^{\circ} \mathrm{C} \pm 0.5^{\circ} \mathrm{C}$ with a rotation speed of $50 \mathrm{rpm}$. Each film was placed and fixed firmly inside the basket. At specified time intervals, i.e., $0.5,1,2,4,8,10,12$, and 15 min aliquots of $5 \mathrm{~mL}$, were withdrawn from each vessel, filtered, and analyzed for CLH by using spectrophotometer (Shimadzu-1700) at $271 \mathrm{~nm}$. The volume in vessel was replenished with fresh buffer $(5 \mathrm{~mL})$ to maintain the sink condition [25].

2.3.9. Differential Scanning Calorimetry (DSC). The thermal behavior of CLH, HPMC E15, and FDBF (F6) optimized batch was investigated using differential scanning calorimetry (DSC 822c, Mettler Toledo). The CLH and HPMC E15 weighing approximately $2 \mathrm{mg}$ were placed in a pan and sealed hermetically with aluminum cover. FDBF (F6) was cut into fine pieces using a sharp cutter. Each sample was then scanned at temperature condition, i.e., 30 to $350^{\circ} \mathrm{C}$ with constant heating rate of $10^{\circ} \mathrm{C} / \mathrm{min}$ using nitrogen gas flow rate of $20 \mathrm{~mL} / \mathrm{min}[26,27]$.

2.3.10. X-Ray Diffraction Study (XRD). XRD was performed to study crystalline behavior of the drug after formulating into a final formulation. The CLH and FDBF (F6) were subjected to X-ray diffraction analysis using X-ray powder diffractometer (XRD-6000; Shimadzu, Japan). The equipment is built with standard $\mathrm{Cu}$ sealed X-ray tube operating with $40 \mathrm{kV}$ voltages and $30 \mathrm{~mA}$ current. The XRD patterns were recorded over the $2 \theta$ range at a scanning rate of $4^{\circ} / \mathrm{min}$ $[28,29]$.

2.3.11. Accelerated Stability Study. Accelerated stability studies were carried out on FDBF (F6) formulation as per International Conference on Harmonization (ICH) Q1A (R2) guidelines. FDBF's formulation was packed in a strip of polyethylene and stored at $75 \pm 5 \% \mathrm{RH}$ and a temperature 40 $\pm 2^{\circ} \mathrm{C}$. At periodic intervals, the formulation was taken out at $0,15,30,60$, and 90 days and analyzed for the following parameters: (a) appearance, (b) folding endurance, (c) drug content, and (d) disintegration time [10, 30].

\section{Result and Discussion}

The CQAs of CLH FDBF are investigated using QbD approach. The prime considerations were given to those parameters which have a significant influence on quality of film formulation. Accordingly, the CQAs of CLH FDBF identified include thickness of film, folding endurance, disintegration time, and drug dissolution. Screening design was carried out to study the influence of each independent variable on respective responses.

3.1. Quality Target Product Profile. QTPP was utilized for identification of critical quality attributes and desired dosage form of CLH (FDBF). CLH FDBF was developed for the management and treatment of hypertension or high blood pressure. QTPP of CLH encompasses safe and efficacious administration of FDBF that facilitates rapid drug action and thereby improves the patient compliance. The technique employed for the preparation of FDBFs was robust and reproducible in nature, and therefore product meets drug product critical quality attributes. Table 2 enlists the QTPP with justifications for their selection.

3.2. Construction of Ishikawa Diagram. Ishikawa diagram was constructed to structure the risk analysis operation for determining the causes and subcauses affecting the CQAs. A risk assessment process was performed to identify high-risk steps that may affect the CQAs of FDBFs; it comprises critical materials attributes (CMA's) and CPPs. Figure 1 illustrates Ishikawa (fish-bone) diagram for CLH FDBFs portraying a cause and effects correlation between the potential factors influencing CQAs of FDBF.

Risk assessment studies have suggested that, among the several process and formulation parameters screened, the formulation parameters such as concentration of polymer $\left(\mathrm{X}_{1}\right)$ and plasticizer $\left(\mathrm{X}_{2}\right)$ were reported to be critical due to associated high risk on selected critical quality attributes, i.e., film thickness $\left(Y_{1}\right)$, disintegration time $\left(Y_{2}\right)$, folding endurance $\left(\mathrm{Y}_{3}\right)$, and tensile strength $\left(\mathrm{Y}_{4}\right)$. Further, fast dissolving buccal film was prepared by using solvent-casting method without employing any sophisticated instrument in the laboratory and hence no such process parameters were reported to have a significant impact on the formulation during all experimentation run. However, several formulations parameters such as sodium lauryl sulphate or citric acid were 
TABLE 2: Quality target product profile (QTPP) earmarked for fast dissolving buccal film of CLH.

\begin{tabular}{|c|c|c|}
\hline QTPP & Target & Justification \\
\hline Dosage form & Buccal Film & $\begin{array}{l}\text { Pharmaceutical requirement; equivalence } \\
\text { same dosage form. }\end{array}$ \\
\hline Route of administration & Buccal Cavity & $\begin{array}{l}\text { Recommended route for delivery of } \\
\text { Clonidine } \mathrm{HCl} \text { to enhance drug } \\
\text { dissolution and bypass the first pass } \\
\text { metabolism. }\end{array}$ \\
\hline Dosage strength & $0.2 \mathrm{mg}$ & $\begin{array}{l}\text { Unit dose of Clonidine } \mathrm{HCl} \text { incorporated } \\
\text { into a single formulation of FDBF }\end{array}$ \\
\hline Dosage Type & $\begin{array}{l}\text { Fast dissolving buccal } \\
\text { film (FDBF) }\end{array}$ & $\begin{array}{l}\text { Faster onset of action leading to } \\
\text { enhanced therapeutic effect. }\end{array}$ \\
\hline Packaging & Polyethylene strip & $\begin{array}{l}\text { Pharmaceutical requirement equivalence } \\
\text { same packaging }\end{array}$ \\
\hline Stability & $\begin{array}{l}\text { At least } 90 \text { days at } \\
\text { room temperature }\end{array}$ & $\begin{array}{l}\text { To maintain therapeutic potential of the } \\
\text { drug during stipulated storage period }\end{array}$ \\
\hline $\begin{array}{l}\text { Alternative routes of } \\
\text { administration }\end{array}$ & None & No other method of administration. \\
\hline
\end{tabular}

reported to involve low or negligible risk and hence were fixed at constant concentration.

3.3. Thickness $\left(Y_{1}\right)$. The thickness of prepared FDBF of CLH was in the range of $0.113 \pm 0.014$ to $0.198 \pm 0.016 \mathrm{~mm}$. Thickness of FDBF could be attributed to film-forming polymer and plasticizer. Impact of both factors on film thickness is depicted in (Figure 2(a)). The results showed HPMC E 15 is key parameter responsible for film thickness. The influence on film thickness was significant and easily observed with increase in HPMC E 15 concentration (Table 3). Moreover, plasticizer is assumed to occupy additional volume and is responsible for disrupting and restructuring of polymer chain imparting thickness to FDBFs [31]. However, the influence of film-forming polymer is considered a significant factor for film thickness compared to amount of plasticizer employed (Table 1). The polynomial equation for film thickness is described as follows:

$$
\text { Film thickness } \begin{aligned}
\left(\mathrm{Y}_{1}\right)= & 0.147+0.023 \mathrm{X}_{1}+0.0186 \mathrm{X}_{2} \\
& +0.009 \mathrm{X}_{1} \mathrm{X}_{2}
\end{aligned}
$$

At increasing the concentration of HPMC E15 $\left(\mathrm{X}_{1}\right)$ and PEG $400\left(\mathrm{X}_{2}\right)$, the film thickness was found to be increased, suggesting both factors have a positive influence on response, while the impact of HPMC E15 $\left(\mathrm{X}_{1}\right)$ was more significant than PEG $400\left(\mathrm{X}_{2}\right)$.

3.4. Disintegration Time $\left(Y_{2}\right)$. Disintegration time (DT) gives an indication about an onset of action which is desirable for oral thin films [24]. DT of all prepared FDBF of CLH was below $28 \pm 2.9$ s, complying the standard mentioned elsewhere [16]. The influence of both factors $\left(\mathrm{X}_{1}\right.$ and $\left.\mathrm{X}_{2}\right)$ showed significant increase in DT $\left(\mathrm{Y}_{2}\right)$ at a higher level. The Figure 2(b) depicts a counter-plot indicating an impact of factors on disintegration time (s). Both factors would be considered while controlling the disintegration time of FDBF. However, HPMC E 15 and PEG 400 at high concentration would produce films which fulfill a condition for fast dissolution. The result is summarized in Table 3. The polynomial equation relating to disintegration time is represented as follows:

$$
\begin{aligned}
& \text { Disintegration time }(\mathrm{sec}) \\
& \quad=24.88+0.5 \mathrm{X}_{1}+3.166 \mathrm{X}_{2}+0.0 \mathrm{X}_{1} \mathrm{X}_{2}
\end{aligned}
$$

The polynomial equation indicated that concentration of HPMC E15 $\left(\mathrm{X}_{1}\right)$ and PEG $400\left(\mathrm{X}_{2}\right)$ also favors the response, but influence of PEG $400\left(\mathrm{X}_{2}\right)$ was more significant as compared to HPMC E15 $\left(\mathrm{X}_{1}\right)$.

3.5. Folding Endurance $\left(Y_{3}\right)$. All prepared FDBF of CLH exhibits folding endurance $269 \pm 5.72$ to $295 \pm 2.28$ times (no), demonstrating good mechanical strength and ensured good flexibility. Film former (HPMC E15) ensures sufficient strength and plasticizer (PEG 400) is responsible for imparting flexibility to film. Therefore, an appropriate concentration of both of these factors would produce a FDBF having desirable quality.

The results indicated that HPMC E15 and PEG 400 have a positive influence on folding endurance (Table 3). PEG 400 is considered main contributing factor for folding endurance, as it causes relaxation of linear polymeric chains possibly by forming hydrogen bonding leading to more flexibility and subsequently high folding endurance numbers [15]. Figure 2(c) demonstrated the impact of HPMC E15 and PEG 400 on folding endurance. The polynomial term for folding endurance is described below:

$$
\begin{aligned}
\text { Folding endurance }= & 281-4.833 \mathrm{X}_{1}+7.5 \mathrm{X}_{2} \\
& -2.75 \mathrm{X}_{1} \mathrm{X}_{2}
\end{aligned}
$$

The polynomial equation suggested that concentration of PEG $400\left(\mathrm{X}_{2}\right)$ has a promising influence on the folding endurance; however, HPMC E15 $\left(\mathrm{X}_{1}\right)$ indicated negative influence on response. The interactive effects of both these factors suggested the negative impact. 

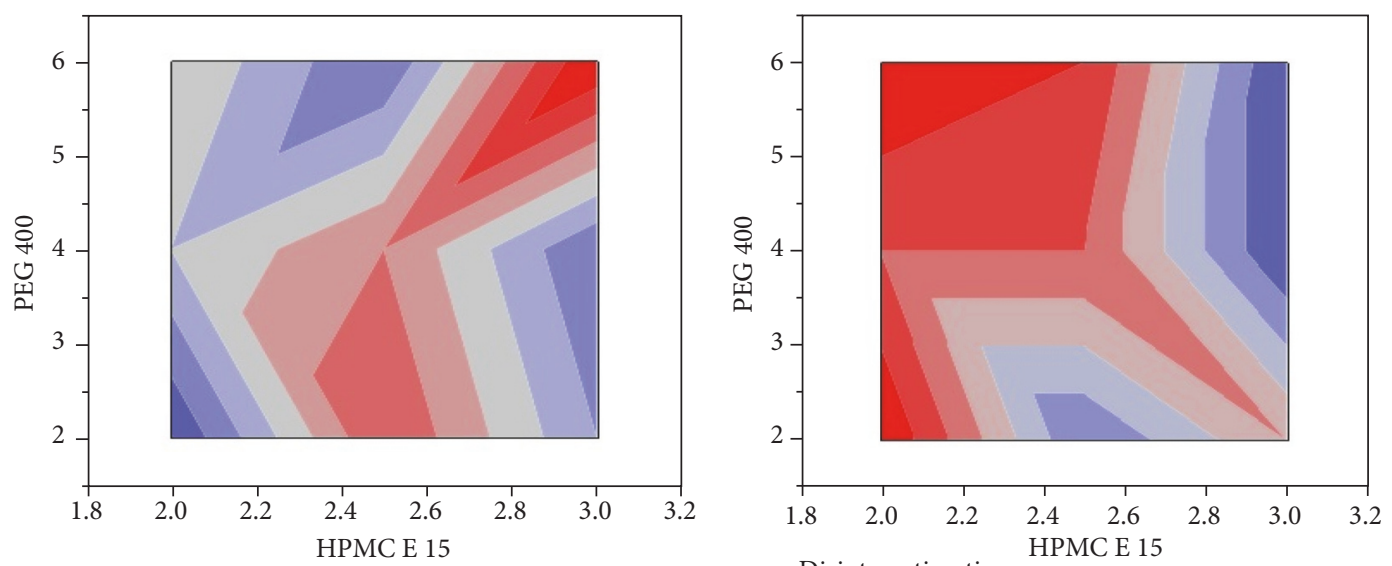

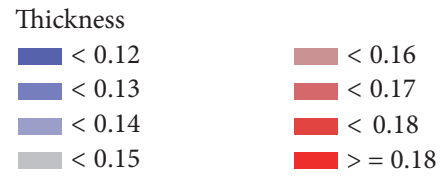

(a)

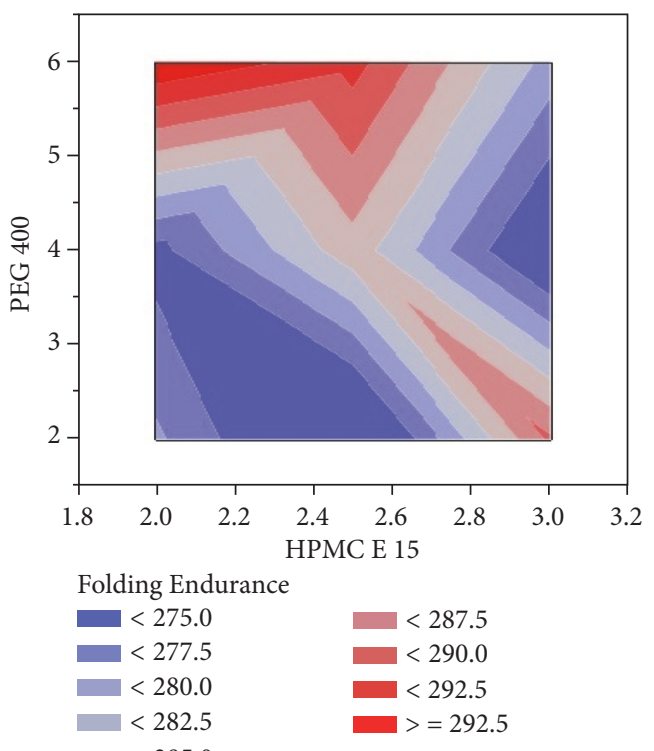

(c)
Disintegration time

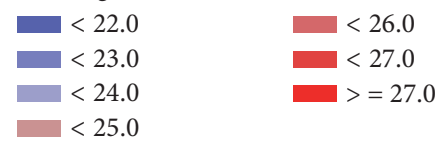

(b)

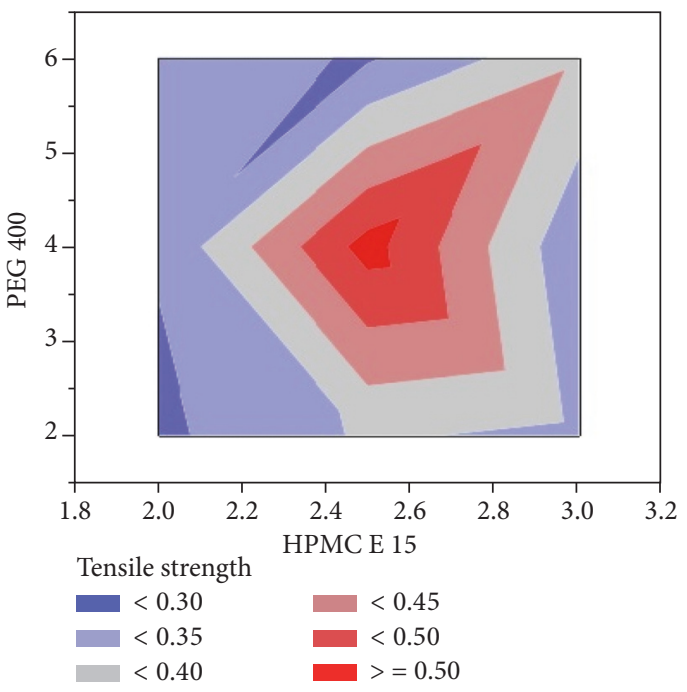

(d)

FIgURE 2: Counter-plot illustrating the influence of HPMC E $15\left(\mathrm{X}_{1}\right)$ and PEG $400\left(\mathrm{X}_{2}\right)$ on (a) thickness, (b) disintegration time, (c) folding endurance, and (d) tensile strength.

3.6. Tensile Strength $\left(Y_{4}\right)$. The tensile strength of prepared FDBF of CLH was in the range $0.289 \pm 0.009$ to $0.392 \pm$ $0.023 \mathrm{~kg}$ (Table 3). Figure 3 depicts the tensile strength of optimized (F6) formulation. Tensile strength is considered a crucial factor for development of FDBF. The nature and amount of plasticizer and film-forming polymer employed would affect tensile strength properties of FDBF. Higher concentration of plasticizer in FDBF results in a high tensile strength and more flexibility of film. Figure 2(d) illustrated the influence of HPMC E15 and PEG 400 on tensile strength. The results revealed that HPMC E 15 and PEG 400 both have positive influence on tensile strength, i.e., an increment in concentrations results into a greater response. However, the role of PEG 400 was considered more significant as it imparts more elasticity and reduces brittleness of FDB. The polynomial equation for tensile strength is given below:

$$
\begin{aligned}
\text { Tensile strength }= & 0.33+0.019 \mathrm{X}_{1}+0.0325 \mathrm{X}_{2} \\
& +0.01 \mathrm{X}_{1} \mathrm{X}_{2}
\end{aligned}
$$

The polynomial equation reveled that concentration of HPMC E15 $\left(\mathrm{X}_{1}\right)$ and PEG $400\left(\mathrm{X}_{2}\right)$ positively improves the tensile strength. Further, PEG $400\left(\mathrm{X}_{2}\right)$ was considered more significant for increasing the tensile strength of the film. 


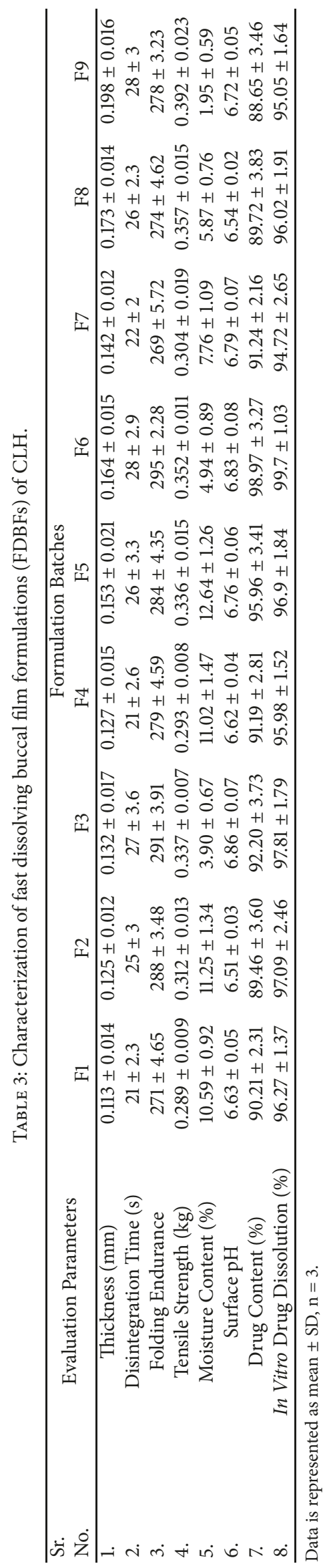




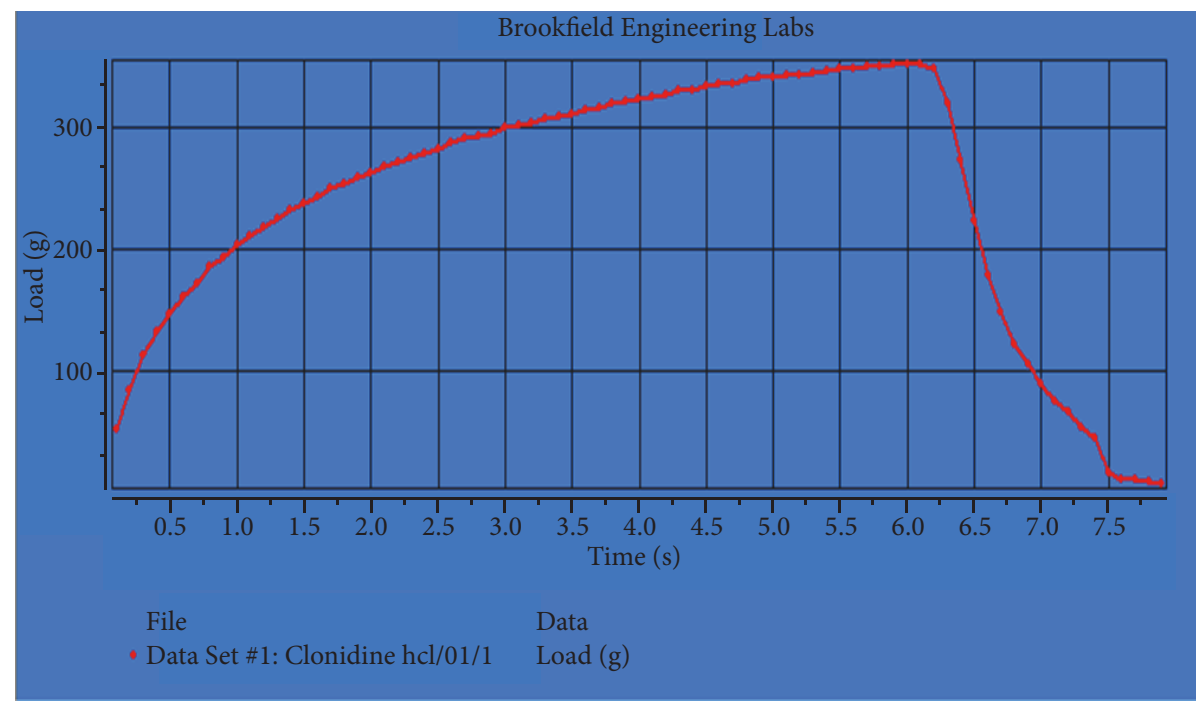

FIGURE 3: Tensile strength of optimized (F6) formulation.

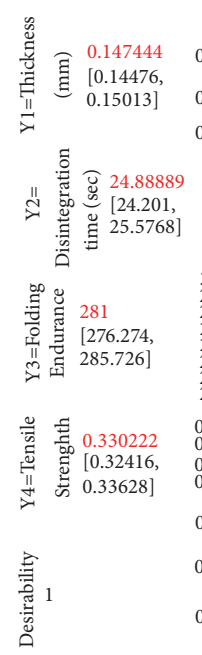

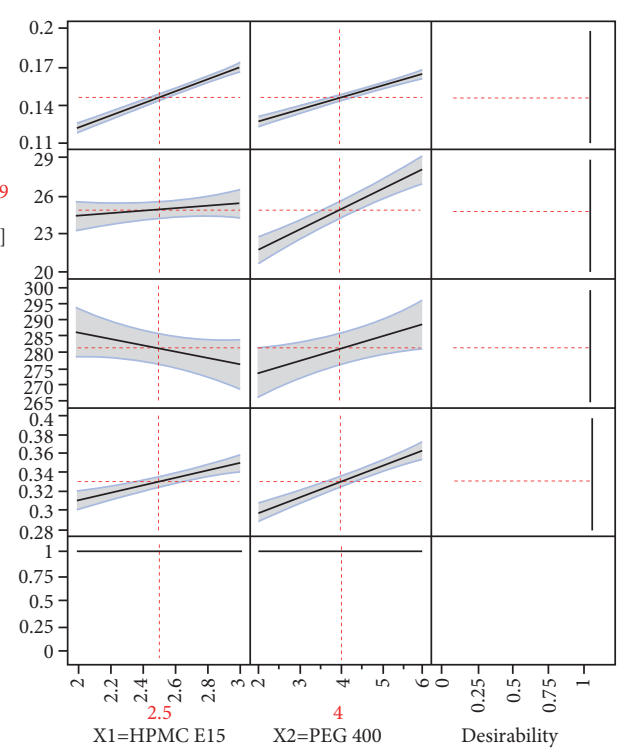

(a) Prediction profiler

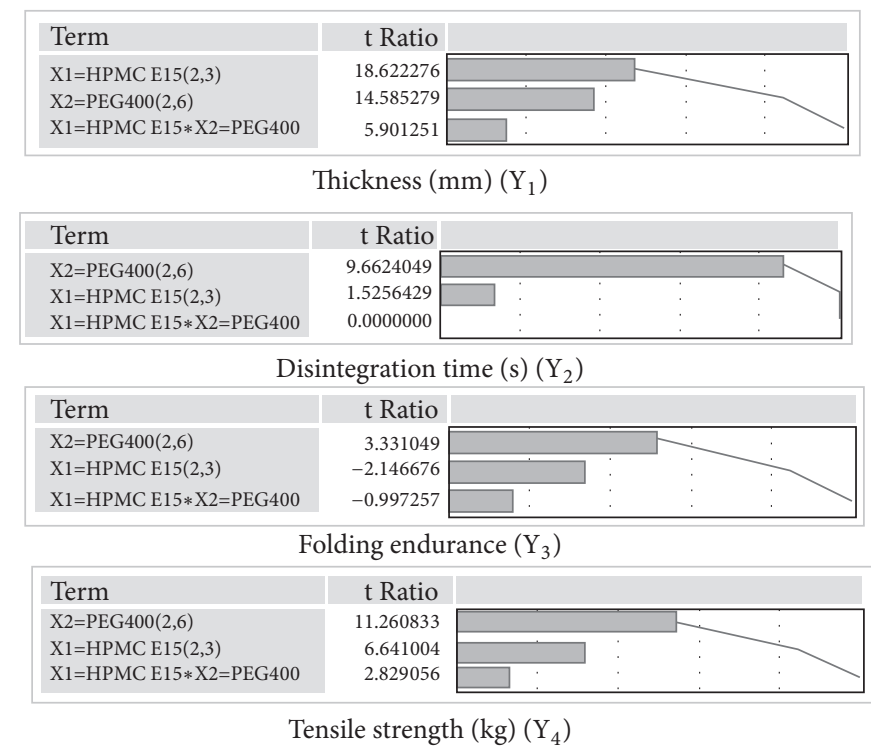

(b) Pareto plot

FIgURE 4: Prediction profiler (4(a)) and standard Pareto plot (4(b)) illustrating the effects HPMC HPMC E $15\left(\mathrm{X}_{1}\right)$ and PEG $400\left(\mathrm{X}_{2}\right)$ on thickness, disintegration time, folding endurance, and tensile strength. The black lines denote the prediction trace; the dotted perpendicular red line corresponds to the current concentration of factor; and the value in red on vertical axis is predicted response based on the current concentration of factor.

3.7. Prediction Profile. The prediction profile (PP) is the easiest way to predict the response surface and also helps to finalize the best formulation composition based on target responses. The $\mathrm{PP}$ is generated for CQAs and is mainly concerned with predicted values which were not examined. Each individual plot or graph shows the prediction values for respective CQAs. This prediction trace indicates the expected variance of response with slight modification in a single variable while others are kept constant. Figure 4(a) represents the prediction profiler for thickness, disintegration time, folding endurance, and tensile strength. The
$\mathrm{X}$-axis represents concentration of factors whereas Y-axis represents/response parameters. The parallel and horizontal line represents predicted values of factors for best possible formulation composition. Figure 4(b) represents Pareto plot showing the influence each individual factor, i.e., $\mathrm{X}_{1}$ and $\mathrm{X}_{2}$, as well as their interactive effects on different responses, i.e., thickness $\left(\mathrm{Y}_{1}\right)$, disintegration time $\left(\mathrm{Y}_{2}\right)$, folding endurance $\left(\mathrm{Y}_{3}\right)$, and tensile strength $\left(\mathrm{Y}_{4}\right)$.

The analysis of variance (ANOVA) was employed to estimate the accuracy of PP. The model was considered significant when the probability value $(\mathrm{P})$ was found to 
TABLE 4: ANOVA result ( $\mathrm{P}$ value) of each response (thickness, folding endurance, disintegration time, and tensile strength).

\begin{tabular}{lccc}
\hline Response & P value & R square & R square Adjusted \\
\hline Thickness (mm) & $<\mathbf{0 . 0 0 0 1}$ & $\mathbf{0 . 9 8}$ & $\mathbf{0 . 5 2}$ \\
Folding endurance (no) & 0.016 & 0.85 & 0.57 \\
Disintegration time (s) & $\mathbf{0 . 0 0 1 1}$ & $\mathbf{0 . 9 5}$ & $\mathbf{0 . 9 1}$ \\
Tensile Strength (g) & $\mathbf{0 . 0 0 0 3}$ & $\mathbf{0 . 9 7}$ & $\mathbf{0 . 6 4}$ \\
\hline
\end{tabular}

The bold and italic fonts are indicating the significance of each model. The $\mathrm{P}$ value $<0.01$ and $R$ square more than 0.6 means very good fit models indicated as bold font, $\mathrm{P}$ value $<0.05$ and $\mathrm{R}$ square value in between 0.4 and 0.6 means good fit models indicated as italic font.

be 0.05 or less; also regression coefficient $\left(\mathrm{R}^{2}\right)$ was closer to 1 . Detailed ANOVA studies are presented in Table 4. The ANOVA revealed that all selected response parameters showed $\mathrm{P}<0.01$ and $\mathrm{R}$ square ( 0.85 to 0.98 ), suggesting all values were significant. Therefore, it can be concluded that the DoE was suited for above study with a good fitting of model.

3.8. Moisture Absorption (\%). The absorption of moisture by a film leads to affecting the film properties. The uptake of moisture originates sticky film may retain on patient fingers or inside of packaging container. Furthermore, presence of moisture in film also affects the disintegration and dissolution behavior; therefore utmost care should be taken to prevent it from moisture. Moisture absorption of developed FDBFs was $1.95 \pm 0.59$ to $12.64 \pm 1.26$ represented in Table 3, indicating very low moisture absorption. However, moisture absorption of film was recognized as medium level CQA because it governs the determination of half-life and storage conditions of final product.

3.9. Drug Content (\%). The drug content (\%) of all FDBFs was in a range of $88.65 \pm 3.46$ to $98.97 \pm 3.27$ (Table 3), indicating uniform dispersion of CLH throughout a film. The good drug content also ensures dose proportionality and uniformity. The limit of drug content is $85-115 \%$ [32].

3.10. Surface $\mathrm{pH}$. The surface $\mathrm{pH}$ of all FDBFs formulations was $6.51 \pm 0.03$ to $6.86 \pm 0.07$ within \pm 0.5 units (Table 3 ), all values were near neutral $\mathrm{pH}$, and therefore no mucosal irritation anticipated consequently helps to build patient comforts and compliance.

3.11. In Vitro Dissolution Study. The in vitro dissolution study of all nine designed formulations of CLH FDBFs revealed faster drug dissolution with more than $90 \%$ of drug dissolved within $8 \mathrm{~min}$ (Figure 5). As stated in literature the optimum time for complete drug dissolution of fast dissolving buccal film should be 10-40 min [31]. The concentration of filmforming polymer and plasticizer influences dissolution process. However, the influence of plasticizer was comparatively more as drug dissolution ascended with an increase in the concentration of plasticizer (Table 3).

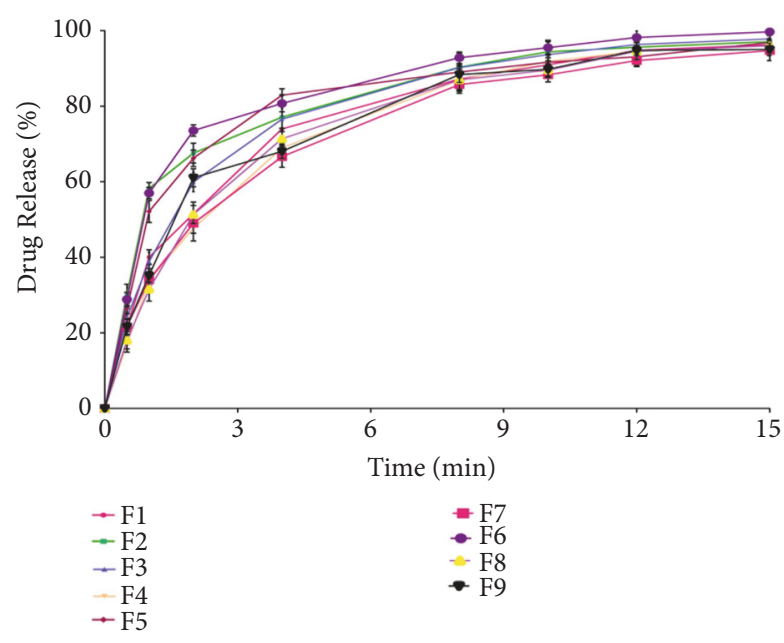

FIGURE 5: In vitro drug dissolution study of fast dissolving films formulations F1 to F9 $(n=3)$.

3.12. Differential Scanning Calorimetry. DSC thermogram of CLH, FDBF (placebo) and optimized formulation of CLH FDBF (F6) is depicted in Figure 6 and thermogram of CLH Figure $6(\mathrm{~A})$ showed a sharp endothermic peak at $312^{\circ} \mathrm{C}$ quit nearer to its melting point, representing crystalline nature of a drug. Figure 6(B) represents thermogram of FDBF (placebo) indicating a broad and diffuse pattern with endothermic peak at $75^{\circ} \mathrm{C}$, possibly due to absence of $\mathrm{CLH}$ in formulation. However, CLH FDBF (F6), in Figure 6(C), showed the absence of sharp crystalline peak of CLH as well as broad endothermic peak (in case of placebo), clearly indicating that $\mathrm{CLH}$ is uniformly distributed and caged in linear chain of film-forming polymer.

3.13. X-Ray Diffraction Study (XRD). The X-ray diffraction spectrum of CLH and optimized FDBF (F6) formulation is presented in Figure 7. CLH showed the characteristic intense peaks at $2 \theta$ angle, namely, 22.35, 25.34, 27.14, 29.24, $30.95,33.98,36.94,40.96,50.12,52.80$, and $54.44^{\circ}$ indicating crystalline nature of drug (Figure 7(a)). The XRD pattern for optimized formulation (F6) of FDBF showed few characteristic diffraction peaks with reduced intensity suggesting the caging of drug in linear chain of film-forming polymer (Figure 7(b)).

3.14. Accelerated Stability Study. The optimized FDBF (F6) formulation was found to be physically and chemically stable at selected temperature and humidity $\left(40 \pm 2^{\circ} \mathrm{C} / 75 \pm 5 \% \mathrm{RH}\right)$ conditions. No significant difference was reported in all investigated parameters, i.e., drug content, folding endurance, and disintegration time along with physical appearance. Table 5 depicts the result of all evaluated parameters before and after storing and all values showed no measurable difference.

\section{Conclusion}

FDBF for CLH was successfully developed and optimized using quality by design approach (QbD). ANOVA study 


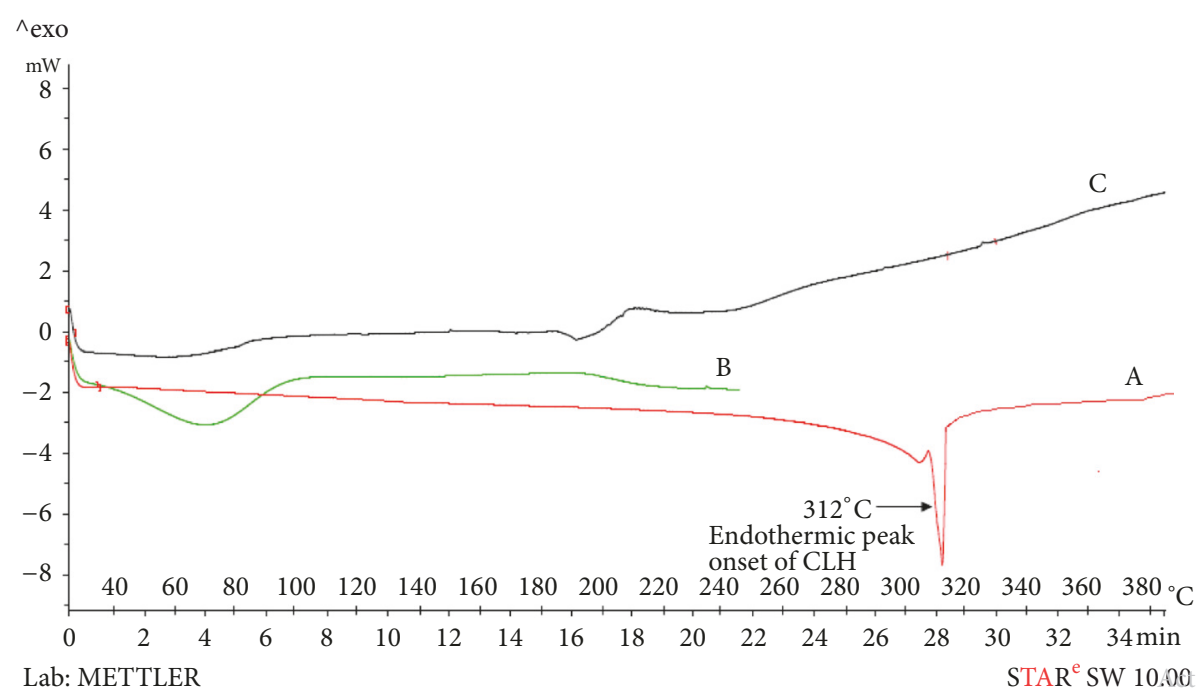

FIGURE 6: DSC thermogram of (A) pure drug (CLH), (B) placebo batch, and (C) optimized FDBF (F6) formulation.

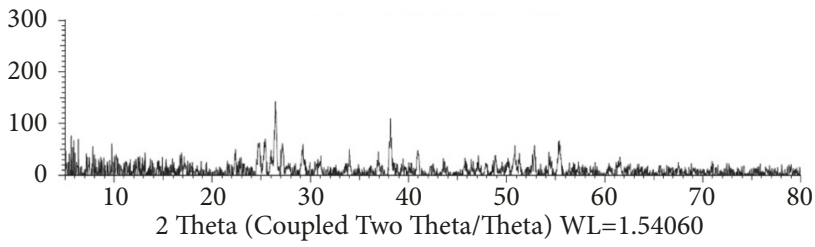

(a)

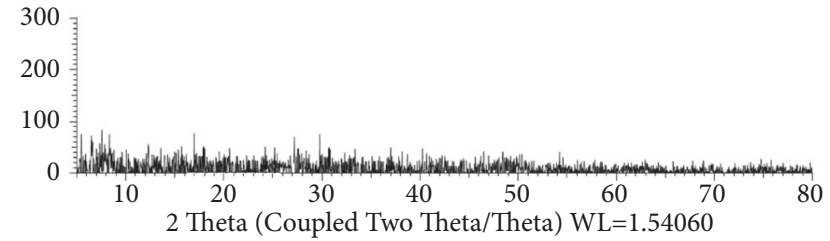

(b)

Figure 7: X-ray diffractogram: (a) pure drug (CLH) and (b) FDBF (F6) formulation.

TABLE 5: Data represents the stability testing parameters of optimized formulation (F6) at accelerated conditions.

\begin{tabular}{|c|c|c|c|c|c|c|}
\hline $\begin{array}{l}\text { Sr. } \\
\text { No. }\end{array}$ & $\begin{array}{l}\text { Evaluation } \\
\text { Parameters }\end{array}$ & $\begin{array}{c}0 \text { days } \\
\text { storage }\end{array}$ & 15 days storage & 30 days storage & 60 days storage & $\begin{array}{l}90 \text { days } \\
\text { storage }\end{array}$ \\
\hline 1 & Physical appearance & Transparent white & Transparent white & Transparent white & Transparent white & Transparent white \\
\hline 2 & Disintegration time (s) & $28 \pm 2.9$ & $26 \pm 1.3$ & $26 \pm 3.5$ & $25 \pm 2.8$ & $23 \pm 5.1$ \\
\hline 3 & Folding endurance & $295 \pm 2.28$ & $291 \pm 3.92$ & $289 \pm 6.42$ & $281 \pm 2.97$ & $278 \pm 5.57$ \\
\hline 4 & Drug content (\%) & $98.97 \pm 3.27$ & $97.65 \pm 2.71$ & $96.14 \pm 1.68$ & $95.52 \pm 3.82$ & $95.09 \pm 2.76$ \\
\hline
\end{tabular}

revealed good fitting of screening model for stated work; furthermore, PP helps to predict the best possible combination of factors with desired targeted responses. JMP ${ }^{\circledR}$ software assisted in design of experiments with appropriate screening model. The optimized FDBF (F6) showed excellent features, like more than $90 \%$ drug dissolution within $8 \mathrm{~min}$. Solid state characterization of F6 formulation by DSC and PXRD indicates a uniform distribution of drug over the film formulation. Furthermore, the accelerated stability testing carried out for three months confirmed robustness of optimized CLH FDBF (F6). Therefore, FDBF for CLH could be sorted as promising alternative for its administration with better patient compliance. However, the detailed studies on pharmacokinetics are further needed to prove clinical effectiveness of CLH containing FDBF.

\section{Data Availability}

The data used to support the findings of this study are available from the corresponding author upon request.

\section{Conflicts of Interest}

The authors report no conflicts of interest.

\section{Acknowledgments}

We thank to Unichem Laboratories Ltd., Goa, India, and Cipla Ltd., Mumbai, India, for providing the gift samples of CLH and Xylitol, respectively. We are also grateful to the Management of R. C. Patel Institute of Pharmaceutical Education and Research, Shirpur, India, for availing all necessary 
instrumental and infrastructural facility for carrying out this research project.

\section{References}

[1] A. L. Goede, R. R. Boedhram, M. Eckhardt et al., "Development and validation of a paediatric oral formulation of clonidine hydrochloride," International Journal of Pharmaceutics, vol. 433, no. 1-2, pp. 119-120, 2012.

[2] A. Potier, J. Voyat, and A. Nicolas, "Stability study of a clonidine oral solution in a novel vehicle designed for pediatric patients," Pharmaceutical Development and Technology, vol. 23, no. 10, pp. 1067-1076, 2018.

[3] M. A. Abounassif, M. S. Mian, and N. A. A. Mian, Analytical Profiles of Drug Substances and Excipients, vol. 21, Academic Press, 1st edition, 1992.

[4] A. Verma, B. Verma, S. Prajapati, and S. Tripathi, "Formulation and evaluation of transdermal therapeutic system of matrix type clonidine hydrochloride," Der Pharmacia Letter, vol. 4, no. 4, pp. 1137-1142, 2012.

[5] B. Vasseur, A. Dufour, L. Houdas et al., "Comparison of the systemic and local pharmacokinetics of clonidine mucoadhesive buccal tablets with reference clonidine oral tablets in healthy volunteers: an open-label randomised cross-over trial," Advances in Therapy, vol. 34, no. 8, pp. 2022-2032, 2017.

[6] K. Gondaliya, P. P. Kapupara, and K. V. Shah, "Development and validation of RP-HPLC method for simultaneous estimation of clonidine hydrochloride and hydrochlorothiazide in pharmaceutical formulation," International Bulletin of Drug Research, vol. 4, no. 6, pp. 106-115, 2014.

[7] S. B. Gondkar, P. Namrata, and R. B. Saudagar, "Fast dissolving oral films," Asian Journal of Pharmaceutical Research, vol. 6, no. 1, pp. 56-58, 2016.

[8] F. E. Cunningham, V. L. Baughman, J. Peters, and C. E. Laurito, "Comparative pharmacokinetics of oral versus sublingual clonidine," Journal of Clinical Anesthesia, vol. 6, no. 5, pp. 430-433, 1994.

[9] G. S. Gilkeson and R. L. Delaney, "Effectiveness of sublingual clonidine in patients unable to take oral medication," Drug Intelligence \& Clinical Pharmacy, vol. 21, no. 3, pp. 262-263, 1987.

[10] H. Chaudhary, S. Gauri, P. Rathee, and V. Kumar, "Development and optimization of fast dissolving oro-dispersible films of granisetron $\mathrm{HCl}$ using Box-Behnken statistical design," Bulletin of Faculty of Pharmacy, Cairo University, vol. 51, no. 2, pp. 193201, 2013.

[11] N. Thakur, M. Bansal, N. Sharma, G. Yadav, and P. Khare, "A novel approach of fast dissolving films and their patients," Advanced Biomedical Research, vol. 7, pp. 50-58, 2013.

[12] R. Bala, P. Pawar, S. Khanna, and S. Arora, "Orally dissolving strips: a new approach to oral drug delivery system," International Journal of Pharmaceutical Investigation, vol. 3, no. 2, pp. 67-76, 2013.

[13] A. Arya, V. Sharma, and K. Pathak, "Pharmaceutical evaluation and dynamic vapor sorption studies of fast dissolving intraoral films of Loratadine," Pharmaceutical Development and Technology, vol. 18, no. 6, pp. 1329-1338, 2013.

[14] A. Alayoubi, L. Haynes, H. Patil, B. Daihom, R. Helms, and H. Almoazen, "Development of a fast dissolving film of epinephrine hydrochloride as a potential anaphylactic treatment for pediatrics," Pharmaceutical Development and Technology, vol. 22, pp. 1012-1016, 2017.
[15] A. F. Borges, B. M. Silva, C. Silva, J. F. Coelho, S. Sim, and S. Simões, "Hydrophobic polymers for orodispersible films: a quality by design approach," Expert Opinion on Drug Delivery, vol. 13, pp. 1357-1374, 2016.

[16] B. M. Silva, S. Vicente, S. Cunha et al., "Retrospective quality by design (rQbD) applied to the optimization of orodispersible films," International Journal of Pharmaceutics, vol. 528, no. 1-2, pp. 655-663, 2017.

[17] A. S. Patil and A. M. Pethe, "Quality by design (QbD): a new concept for development of quality pharmaceuticals," International Journal of Pharmaceutical Quality Assurance, vol. 4, pp. 13-19, 2013.

[18] S. Karki, H. Kim, S. J. Na, D. Shin, K. Jo, and J. Lee, “Thin films as an emerging platform for drug delivery," Asian Journal of Pharmaceutical Sciences, vol. 11, no. 5, pp. 559-574, 2016.

[19] M. I. Mohamed, M. Haider, and M. M. J. Ali, "Buccal mucoadhesive films containing antihypertensive drug: in vitro/in vivo evaluation," Journal of Chemical and Pharmaceutical Research, vol. 3, pp. 665-686, 2011.

[20] R. P. Dixit and S. P. Puthli, "Oral strip technology: overview and future potential," Journal of Controlled Release, vol. 139, no. 2, pp. 94-107, 2009.

[21] M. Irfan, S. Rabel, Q. Bukhtar, M. I. Qadir, F. Jabeen, and A. Khan, "Orally disintegrating films: a modern expansion in drug delivery system," Saudi Pharmaceutical Journal, vol. 24, no. 5, pp. 537-546, 2015.

[22] M. Hanif, M. Zaman, and V. Chaurasiya, "Polymers used in buccal film: a review," Designed Monomers and Polymers, vol. 18, no. 2, pp. 105-111, 2015.

[23] F. Cilurzo, I. E. Cupone, P. Minghetti, F. Selmin, and L. Montanari, "Fast dissolving films made of maltodextrins," European Journal of Pharmaceutics and Biopharmaceutics, vol. 70, no. 3, pp. 895-900, 2008.

[24] G. P. Kumar, A. R. Phani, R. G. S. V. Prasad, J. S. Sanganal et al., "Polyvinylpyrrolidone oral films of enrofloxacin: film characterization and drug release," International Journal of Pharmaceutics, vol. 471, no. 1-2, pp. 146-152, 2014.

[25] R. C. Mashru, V. B. Sutariya, M. G. Sankalia, and P. P. Parikh, "Development and evaluation of fast-dissolving film of salbutamol sulphate," Drug Development and Industrial Pharmacy, vol. 31, no. 1, pp. 25-34, 2005.

[26] A. Abruzzo, F. P. Nicoletta, F. Dalena, T. Cerchiara, B. Luppi, and F. Bigucci, "Bilayered buccal films as child-appropriate dosage form for systemic administration of propranolol," International Journal of Pharmaceutics, vol. 531, no. 1, pp. 257-265, 2017.

[27] A. D. Chonkar, J. V. Rao, R. S. Managuli et al., "Development of fast dissolving oral films containing lercanidipine $\mathrm{HCl}$ nanoparticles in semicrystalline polymeric matrix for enhanced dissolution and ex vivo permeation," European Journal of Pharmaceutics and Biopharmaceutics, vol. 103, pp. 179-191, 2016.

[28] W. Samprasit, P. Akkaramongkolporn, R. Kaomongkolgit, and P. Opanasopit, "Cyclodextrin-based oral dissolving films formulation of taste-masked meloxicam," Pharmaceutical Development and Technology, vol. 23, pp. 530-539, 2018.

[29] E. M. Maher, A. M. A. Ali, H. F. Salem, and A. A. Abdelrahman, "In vitro/in vivo evaluation of an optimized fast dissolving oral film containing olanzapine co-amorphous dispersion with selected carboxylic acids," Drug Delivery, vol. 23, no. 8, pp. 3088-3100, 2016.

[30] H. Shimoda, K. Taniguchi, M. Nishimura et al., "Preparation of a fast dissolving oral thin film containing dexamethasone: 
a possible application to antiemesis during cancer chemotherapy," European Journal of Pharmaceutics and Biopharmaceutics, vol. 73, no. 3, pp. 361-365, 2009.

[31] S. Mazumder, N. Pavurala, P. Manda, X. Cruz, C. N. Xu, and Y. S. Krishnaiah, "Quality by Design approach for studying the impact of formulation and process variables on product quality of oral disintegrating films," International Journal of Pharmaceutics, vol. 527, no. 1-2, pp. 151-160, 2017.

[32] S. Salehi and S. Boddohi, "New formulation and approach for mucoadhesive buccal film of rizatriptan benzoate," Progress in Biomaterials, vol. 6, no. 4, pp. 175-187, 2017. 


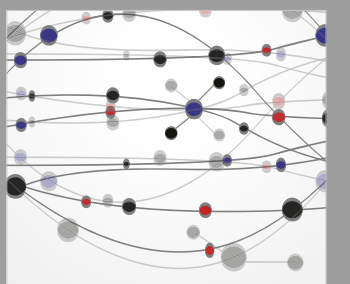

The Scientific World Journal
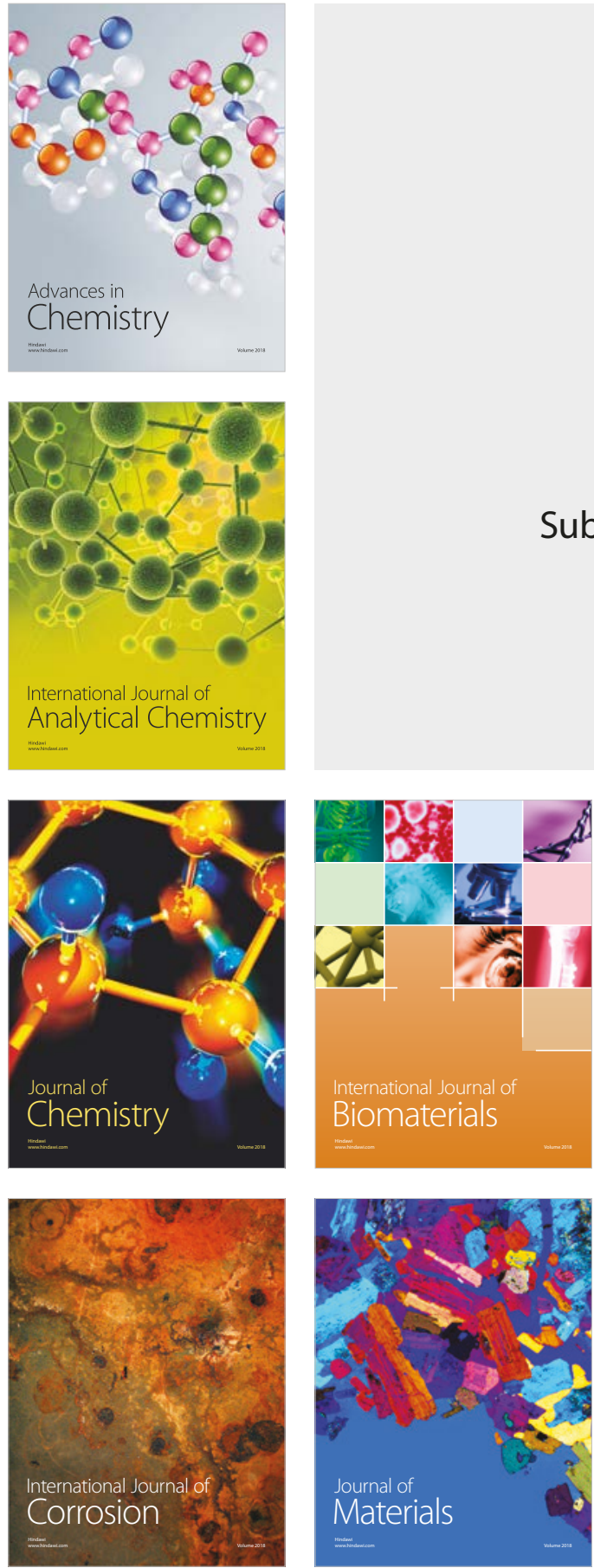

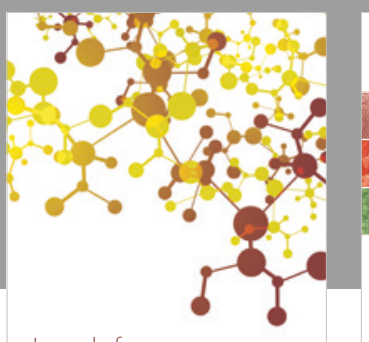

Journal of

Applied Chemistry
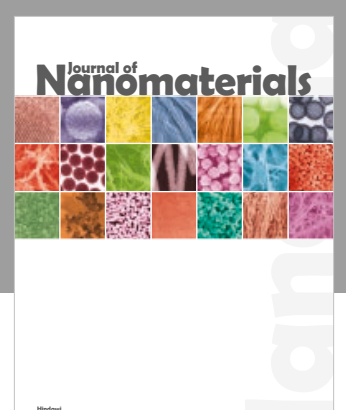

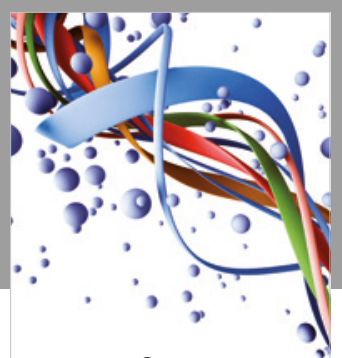

Scientifica

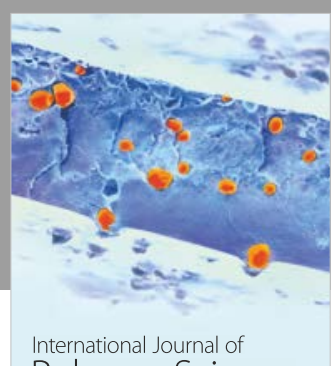

Polymer Science

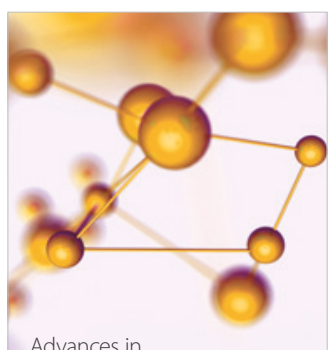

Physical Chemistry
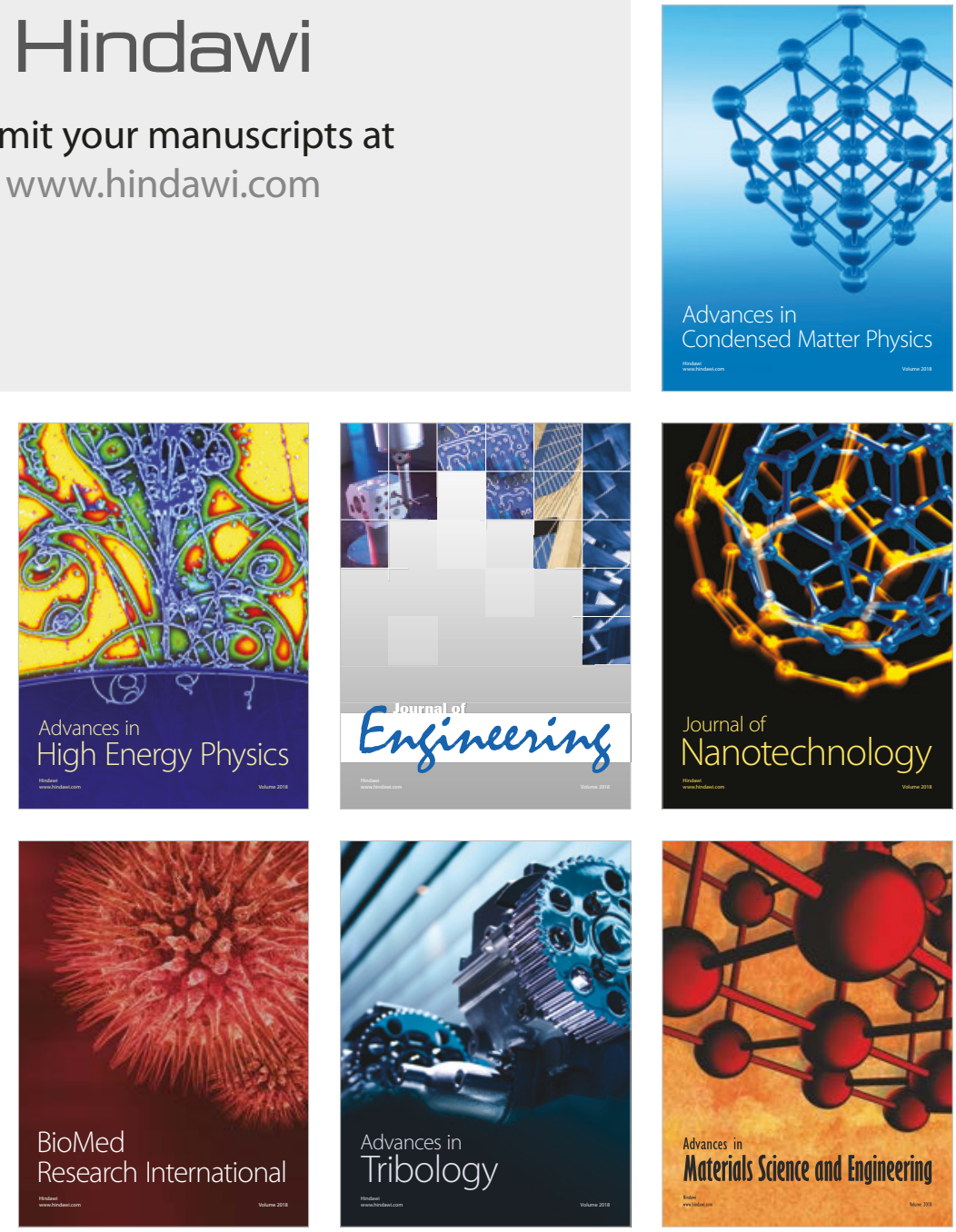